\title{
Bronchodilator responsiveness and serum total IgE levels in families of probands with severe early-onset COPD
}

\author{
J.C. Celedon*, ${ }^{*+}$, F.E. Speizer*,++, J.M. Drazen**,++, S.T. Weiss*,++, E.J. Campbell ${ }^{\dagger}$, V.J. Carey*, \\ J.J. Reilly**,++, L. Ginns ${ }^{+,++}$, E.K. Silverman*,**,
}

Bronchodilator responsiveness and serum total IgE levels in families of probands with severe, early-onset COPD. J.C. Celedon, F.E. Speizer, J.M. Drazen, S.T. Weiss, E.J Campbell, V.J. Carey, J. Reilly, L. Ginns, E.K. Silverman. (C)ERS Journals Ltd 1999.

ABSTRACT: Bronchodilator responsiveness has been associated with a subsequent accelerated decline in forced expiratory volume in one second (FEV1). Therefore, bronchodilator responsiveness and total serum immunoglobulin $\mathrm{E}$ (IgE) levels were assessed in $\mathbf{1 8 4}$ adult first-degree relatives of probands with severe early-onset chronic obstructive pulmonary disease (COPD) and a control group.

Greater bronchodilator responsiveness was found among current smokers or exsmokers who were first-degree relatives of early-onset COPD probands than in currently or exsmoking controls, expressed as increase in FEV1 as a percentage of baseline (5.8 \pm 8.1 versus $2.9 \pm 5.1 \%, p<0.01$ ), absolute increase in FEV1 from baseline $(120 \pm 130$ versus $60 \pm 110 \mathrm{~mL}, p<0.05)$, and increase in $F E V 1$ as a percentage of the predicted value (3.6 \pm 4.1 versus $2.2 \pm 3.9 \%$, $\mathrm{p}<0.05)$. However, elevated total serum $\operatorname{IgE}$ levels were not found in first-degree relatives of early-onset COPD probands compared with control subjects.

The increased bronchodilator responsiveness among currently smoking/exsmoking first-degree relatives of early-onset COPD probands suggests that these individuals may have enhanced susceptibility to the detrimental effects of cigarette smoking.

Eur Respir J 1999; 14: 1009-1014.

\begin{abstract}
*Channing Laboratory **Division of Pulmonary and Critical Care Medicine, Dept of Medicine, Brigham and Women's Hospital +Pulmonary and Critical Care Unit, Dept of General Medical Services, Massachusetts General Hospital ${ }^{++}$Harvard Medical School, Boston, MA Dept of Internal Medicine, University of Utah Health Services Center, Salt Lake City, UT, USA.

Correspondence: E.K. Silverman, Channing Laboratory Brigham and Women's Hospital 181 Longwood Avenue Boston MA 02115 Fax: 16175250958

Keywords: Bronchodilator response, chronic obstructive pulmonary disease, familial aggregation, genetic epidemiology, genetics, immunoglobulin E

Received: November 231998

Accepted after revision July 111999

This study was supported by an American Lung Association Research Grant (E.K. Silverman) and National Institutes of Health grants NCRR GCRC MO1 RR02635 to the Brigham and Women's Hospital General Clinical Research Center and HL46440 (E.J. Campbell) to the University of Utah Health Sciences Center. J.C. Celedon is supported by Sciences Center. J.C. Celedon is supported by National Research Service Award Grant HL07427.
\end{abstract}

Chronic obstructive pulmonary disease (COPD), the fourth leading cause of death in the USA $[1,2]$ and a growing international problem, is strongly associated with cigarette smoking [3]. Even though tobacco use is a well-known risk factor for COPD [4], the development of airflow obstruction in response to smoking is highly variable [5], and it has been postulated that individuals may vary in their genetic susceptibility to COPD [3]. In a previous report on individuals without severe $\alpha_{1}$-antitrypsin deficiency, increased risk of airflow obstruction and chronic bronchitis was found in current smokers and exsmokers who were first-degree relatives of probands with severe early-onset COPD, compared with appropriate control subjects [6]. Thus, the findings of the authors and others [7-13] suggest that familial factors, probably genetic, contribute to the development of COPD.

Bronchodilator responsiveness, a physiological response that differs from airway responsiveness to bronchoconstrictors, has been associated with a subsequent accelerated decline in forced expiratory volume in one second (FEV1) [14-17]. Thus, bronchodilator responsiveness may be associated with an increased risk of either acquiring COPD or developing the disease at an earlier age in susceptible individuals who smoke.
Higher total serum immunoglobulin E (IgE) levels have previously been demonstrated in first degree relatives of PI $\mathrm{Z}$ subjects with COPD than in first-degree relatives of PI Z subjects without COPD [18]. This report presents a comparison of bronchodilator responsiveness and total serum IgE levels in 184 adult first-degree relatives of 44 probands with severe early-onset COPD (without severe $\alpha_{1}$-antitrypsin deficiency) and 83 adult control subjects.

\section{Methods}

\section{Study participants}

The screening and enrolment procedures for subjects participating in the study have been described elsewhere [6]. In brief, 44 probands with severe early-onset COPD were identified from lung transplant programmes, lung volume reduction surgery programmes and pulmonary clinics at participating hospitals. The enrolment criteria for probands with COPD included: FEV $1<40 \%$ of the predicted value, age $<53 \mathrm{yrs}$, and the absence of severe $\alpha_{1}$-antitrypsin deficiency (e.g., PI Z, PI null-null). Subjects were excluded if they had already undergone lung volume reduction surgery or lung transplantation. 
For the 44 probands with early-onset COPD, all available first-degree relatives were invited to enroll; 203 firstdegree relatives ( 28 parents, 91 siblings and 84 children) of COPD probands were recruited.

Control probands, all of whom were current smokers or exsmokers, were recruited from prior population-based studies in Watertown and East Boston, MA, USA [19, 20]. The spouses and first-degree relatives of the control probands were asked to participate. Twenty control probands, 54 first-degree relatives and nine spouses comprised the comparison group for first-degree relatives of early-onset COPD probands.

Since there were no subjects younger than 18 yrs of age in the control group, first-degree relatives of early-onset COPD probands who were $<18$ yrs of age $(n=19)$ were excluded from this analysis.

After giving written informed consent, all study subjects completed a protocol that included a questionnaire, spirometry and giving a blood sample. Over $90 \%$ of the protocols were performed at the subjects' homes. The study protocol was approved by the Human Research Committee of Brigham and Women's Hospital in Boston.

\section{Questionnaire}

Each participant completed a modified version of the 1978 American Thoracic Society Division of Lung Diseases Respiratory Disease Questionnaire including questions on passive smoking and diet [21]. The intensity of cigarette smoking in pack-yrs was calculated as the product of the period of tobacco use (in yrs) and the average number of cigarettes smoked per day, which was divided by 20 to convert to packs.

\section{Spirometry}

A Survey Tach Spirometer (Warren E. Collins, Braintree, MA, USA) was used to perform spirometry in a standardized manner, with subjects seated and wearing a noseclip. As many as eight attempts were performed by each participant in order to obtain three acceptable measures. Spirometry was performed in accordance with American Thoracic Society specifications [22]; the FEV1/forced vital capacity from the best test effort and the highest FEV1 value are reported. Height was measured in stockinged feet to the nearest $0.5^{\prime \prime}(1.3 \mathrm{~cm})$. Subjects were told to avoid bronchodilator use for $\geq 4 \mathrm{~h}$ prior to the test, unless significant respiratory symptoms required bronchodilator treatment.

Spirometry was repeated after inhalation of $180 \mu \mathrm{g}(2$ puffs) albuterol using a spacer device. The time elapsed between the last effort measured prior to bronchodilator challenge and the first effort following administration of albuterol was recorded. A subject's response to bronchodilator challenge was expressed as [1] a percentage of baseline FEV1, calculated using change in $(\Delta) \mathrm{FEV} 1=(($ postbronchodilator FEV1 - baseline FEV1)/baseline FEV1) $\times$ $100 ; 2)$ an absolute value in $\mathrm{mL}$, calculated using: $\Delta$ FEV1=postbronchodilator FEV1 -baseline FEV1; and 3) a percentage of the predicted value ofFEV1, calculated using $\Delta \mathrm{FEV} 1=(($ postbronchodilator FEV1 - baseline FEV1)/predicted FEV1) $\times 100$.

Pulmonary function test results were expressed as a percent of the predicted values using the equations of CRAPO et al. [23].

\section{Total serum immunoglobulin E levels}

Serum total IgE levels were determined by means of the UniCAP 100 system (Pharmacia \& Upjohn, Kalamazoo, MI, USA). All values obtained were transformed to a $\log 10$ scale for analysis, in accordance with the recognized logarithmic distribution of total serum IgE levels in the general population.

\section{Statistical methods}

Student's t-tests and simple linear regression were performed using the SAS statistical package (SAS Statistical Institute, Cary, NC, USA) on a Sun microsystem (Sun Microsystems, Mountain View, CA, USA). Since multiple subjects from each family were included, standard regression analysis was not appropriate for assessing the influence of relationship to a proband with early-onset COPD on the phenotypes of interest [6]. Therefore, generalized estimating equations (GEEs) from the SAS Statistical Institute (GEE Version 2.03, Hiedelberg Macro), adjusting for various covariates, were employed to study the differences in bronchodilator responsiveness and total serum IgE levels (expressed as quantitative traits) between first-degree relatives of early-onset COPD probands and control subjects.

\section{Results}

Comparison of adult first-degree relatives of probands with severe early-onset chronic obstructive pulmonary disease and control subjects

The 184 adult first-degree relatives of probands with severe early-onset COPD (mean FEV $1=83.1 \pm 20.3 \%$ pred) were compared with 83 control family members (mean FEV1 $=91.0 \pm 14.4 \%$ pred) (table 1 ). There were no differences in total serum IgE levels between first-degree relatives of early-onset COPD probands and control subjects $(\mathrm{p}=$ 0.07 ). There was greater bronchodilator responsiveness in

Table 1. - Demographics, bronchodilator responsiveness and serum immunoglobulin $E$ (lgE) levels of adult first-degree relatives of chronic obstructive pulmonary disease (COPD) probands compared with controls

\begin{tabular}{lccccccc}
\hline & $\begin{array}{c}\text { Subjects } \\
\mathrm{n}\end{array}$ & Age yrs & $\begin{array}{c}\text { Smoking } \\
\text { duration pack-yrs }\end{array}$ & $\begin{array}{c}\Delta \text { FEV1 } \\
\% \text { baseline }\end{array}$ & $\begin{array}{c}\Delta \text { FEV1 } \\
\% \text { pred }\end{array}$ & $\begin{array}{c}\Delta \text { FEV1 } \\
\text { L }\end{array}$ & $\begin{array}{c}\text { Log10 IgE } \\
\text { IU.mL }\end{array}$ \\
\hline $\begin{array}{l}\text { First-degree relatives of } \\
\text { COPD probands }\end{array}$ & 184 & $43.7 \pm 17.4$ & $17.3 \pm 25.0$ & $4.9 \pm 7.2$ & $3.3 \pm 4.1$ & $0.11 \pm 0.14$ & $1.53 \pm 0.69$ \\
All controls & 83 & $45.0 \pm 16.3$ & $12.8 \pm 20.0$ & $3.2 \pm 5.5^{*}$ & $2.5 \pm 3.9$ & $0.08 \pm 0.12^{*}$ & $1.69 \pm 0.63$ \\
\hline
\end{tabular}

Data are presented as mean \pm SD. $\triangle \mathrm{FEV} 1$ : change in forced expiratory volume in one second. $*$ : $\mathrm{p}<0.05$ versus first-degree relatives of COPD probands. 
first-degree relatives of early-onset COPD probands than in control subjects, expressed as $\triangle \mathrm{FEV} 1$ as a percentage of baseline $(\mathrm{p}<0.05)$ or as an absolute value $(\mathrm{p}<0.05)$.

In order to determine whether tobacco use influenced bronchodilator responsiveness and total serum IgE levels, first-degree relatives of early-onset COPD probands and control subjects were compared after stratification by smoking (table 2). There were no significant differences in bronchodilator responsiveness and total serum IgE levels between nonsmoking first-degree relatives of COPD probands and nonsmoking control subjects. In contrast, currently smoking or exsmoking first-degree relatives of COPD probands had greater bronchodilator responsiveness than currently or exsmoking control subjects, expressed as $\triangle F E V 1$ as a percentage of baseline $(p<0.01)$, an absolute value $(\mathrm{p}=0.01)$, or a percentage of the predicted value $(\mathrm{p}<0.05)$.

Figure 1 illustrates the relationship between the absolute value of $\triangle F E V 1$ and measured baseline FEV1 among current/exsmoking first-degree relatives of COPD probands and currently smoking/exsmoking controls. Figure 2 illustrates the same relationship among nonsmoking first-degree relatives of COPD probands and nonsmoking control subjects. In both first-degree relatives of COPD probands and control subjects, the absolute value of $\triangle F E V 1$ and measured baseline FEV1 were not significantly correlated, regardless of smoking habits.

Multivariate analysis of the association between bronchodilator responsiveness and relationship to probands with severe, early-onset chronic obstructive pulmonary disease

GEEs were employed to study the association between bronchodilator responsiveness and relationship to an earlyonset COPD proband (table 3). After adjustment for age, sex, and intensity of smoking (in pack-yrs), there was no significant difference in $\triangle \mathrm{FEV} 1$ as a percentage of the predicted value between first-degree relatives of earlyonset COPD probands and control subjects (model 1). Former or current smokers who were first-degree relatives of early-onset COPD probands had a greater $\triangle \mathrm{FEV} 1$ as a percentage of the predicted value than current smokers or exsmoking controls (model 2). No significant difference in $\triangle F E V 1$ as a percentage of the predicted value was observed when nonsmoking first-degree relatives of earlyonset COPD probands and nonsmoking controls were compared (model 3).

Multivariate analyses with $\triangle \mathrm{FEV} 1$ as an absolute value and as a percentage of baseline as outcomes were also per-

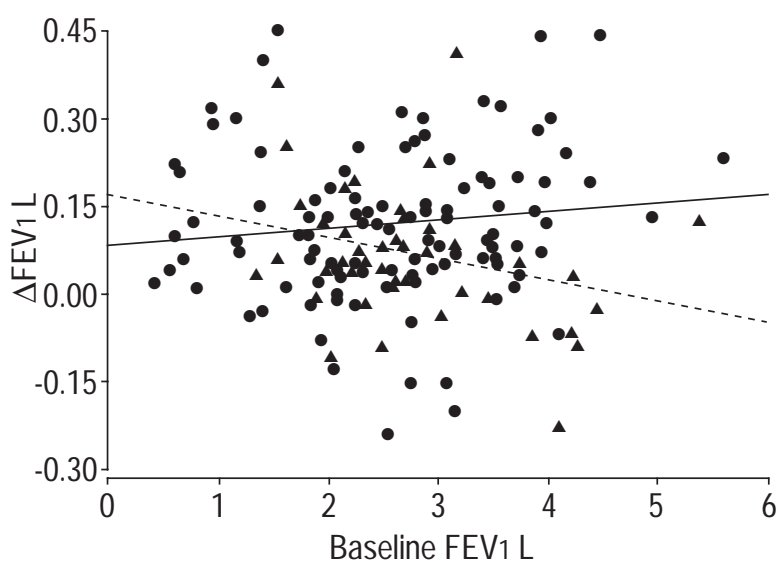

Fig. 1. - Correlation between change in $(\Delta)$ forced expiratory volume in one second (FEV1) following bronchodilator challenge and measured baseline FEV1 in current/exsmoking adult first-degree relatives of chronic obstructive pulmonary disease probands $(\bullet:-$ : regression line; Spearman $=0.14, \mathrm{p}=0.14)$ and current/exsmoking controls $(\boldsymbol{\Delta} ;---$ : regression line $=0.22, \mathrm{p}=0.14$ ).

formed. After adjustment for age, sex, height and intensity of smoking, currently smoking or exsmoking first-degree relatives of early-onset COPD probands had a significantly greater $\triangle \mathrm{FEV} 1$ than currently smoking or exsmoking controls (difference in $\triangle \mathrm{FEV} 154 \mathrm{~mL}, 95 \%$ confidence interval (CI) $10.5-96.7 \mathrm{~mL}, \mathrm{p}=0.01 ; 3.4 \%$, 95\% CI $1.1-5.8 \%$, $\mathrm{p}<0.01)$. The addition of measured baseline FEV1 to these multivariate models did not appreciably change the difference in $\triangle F E V 1$ as an absolute value between the two groups; however, there was no longer a significant difference in $\triangle F E V 1$ as a percentage of baseline when measured baseline FEV1 was included in the models.

Because the control group included 18 subjects with physician-diagnosed asthma, multivariate analyses of the association between bronchodilator responsiveness and relationship to early-onset COPD probands, adjusting for age, sex, duration of smoking and measured baseline FEV1 were repeated after excluding asthmatic subjects from the control group. Former or current smokers who were firstdegree relatives of early-onset COPD probands had greater bronchodilator responsiveness than currently smoking or exsmoking control subjects, expressed as $\triangle \mathrm{FEV} 1$ as an absolute value or as a percentage of the predicted value (difference $55 \mathrm{~mL}, 95 \%$ CI 13.7-96.0 mL, p $<0.01 ; 1.4 \%$ pred, 95\% CI $0.1-2.7 \%$ pred, $\mathrm{p}=0.03$ ), and a trend for $\triangle \mathrm{FEV} 1$ as a percentage of baseline $(1.9 \%, 95 \% \mathrm{CI}-0.3-$ $4.1 \%, \mathrm{p}=0.08)$.

Table 2. - Demographics, bronchodilator responsiveness and total serum immunoglobulin $E$ (IgE) levels of adult firstdegree relatives of chronic obstructive pulmonary disease (COPD) probands compared with controls stratified by smoking

\begin{tabular}{|c|c|c|c|c|c|c|}
\hline $\begin{array}{c}\text { Subjects } \\
\mathrm{n}\end{array}$ & Age yrs & $\begin{array}{l}\text { Smoking } \\
\text { duration } \\
\text { pack-yrs }\end{array}$ & $\begin{array}{c}\Delta \mathrm{FEV} 1 \\
\% \text { baseline }\end{array}$ & $\begin{array}{l}\Delta \mathrm{FEV} 1 \\
\% \text { pred }\end{array}$ & $\underset{\mathrm{L}}{\Delta \mathrm{FEV} 1}$ & $\begin{array}{c}\log 10 \\
\operatorname{IgE}\end{array}$ \\
\hline
\end{tabular}

Smoking first-degree

relatives

Smoking controls

Nonsmoking first-degree

relatives

111

48

Nonsmoking controls
73

$39.9 \pm 18.2$
$39.9 \pm 17.3$

$46.2 \pm 17.1 \quad 28.7 \pm 26.6$

$22.1 \pm 22.1$

$0.0 \pm 0.0$

$0.0 \pm 0.0$
$5.8 \pm 8.1$

$2.9 \pm 5.1 * *$

$3.6 \pm 4.1$

$2.2 \pm 3.9 *$

$0.12 \pm 0.31$

$0.06 \pm 0.11^{*}$

$3.4 \pm 5.3$

$3.6 \pm 6.1$

$0.10 \pm 0.15$

$1.56 \pm 0.73$

$1.70 \pm 0.65$

Data are presented as mean \pm SD. $\Delta$ FEV1: change in forced expiratory volume in one second. $*: \mathrm{p}<0.05, * *: \mathrm{p}<0.01$ versus first-degree relatives of COPD probands with similar smoking history. 
Table 3. - Multivariate analysis of the association between change in forced expiratory volume in one second after bronchodilator challenge, expressed as a percentage of the predicted value and relationship to chronic obstructive pulmonary disease (COPD) probands

\begin{tabular}{llrr}
\hline GEE model & Variables & Regression coefficient (95\% CI) & p-value \\
\hline $\begin{array}{l}\text { Model 1: all adult first-degree relatives } \\
\text { of COPD probands compared with all } \\
\text { controls }\end{array}$ & First-degree relatives of COPD & $1.01(-0.14-2.16)$ & 0.08 \\
& probands & & $0.72(-0.43-1.87)$ \\
& Female sex & $-0.01(-0.05-0.03)$ & 0.72 \\
& Age & $0.01(-0.02-0.03)$ & 0.60 \\
Model 2: smoking adult first-degree & First-degree relatives of COPD & $1.60(0.17-3.00)$ & 0.03 \\
$\begin{array}{l}\text { relatives of COPD probands compared } \\
\text { with smoking controls }\end{array}$ & probands & & 0.02 \\
& Female sex & $1.60(0.34-2.87)$ & 0.82 \\
& Age & $-0.01(-0.06-0.04)$ & 0.74 \\
Model 3: nonsmoking adult first-degree & Sirst-degree relatives of COPD & $0.004(-0.02-0.03)$ & 0.68 \\
relatives of COPD probands compared & probands & $0.31(-1.61-1.71)$ & 0.57 \\
with nonsmoking controls & Female sex & & $0.54(-2.43-1.34)$ \\
& Age & $-0.01(-0.06-0.04)$ & 0.64 \\
\hline
\end{tabular}

*: in pack-yrs. CI: confidence intervals.

Multivariate analysis of the association between total serum immunoglobulin E level and relationship to probands with severe early-onset chronic obstructive pulmonary disease

Using GEEs, the association between total serum IgE levels and relationship to early-onset COPD probands was examined. After adjustment for sex, duration of smoking and age, there were no significant differences in $\log 10 \mathrm{IgE}$ between first-degree relatives of early-onset COPD probands and controls. These results were not appreciably changed after excluding the 18 asthmatic subjects from the control group.

\section{Discussion}

Even though the natural history of COPD is distinctly influenced by tobacco use, only a minority of smokers

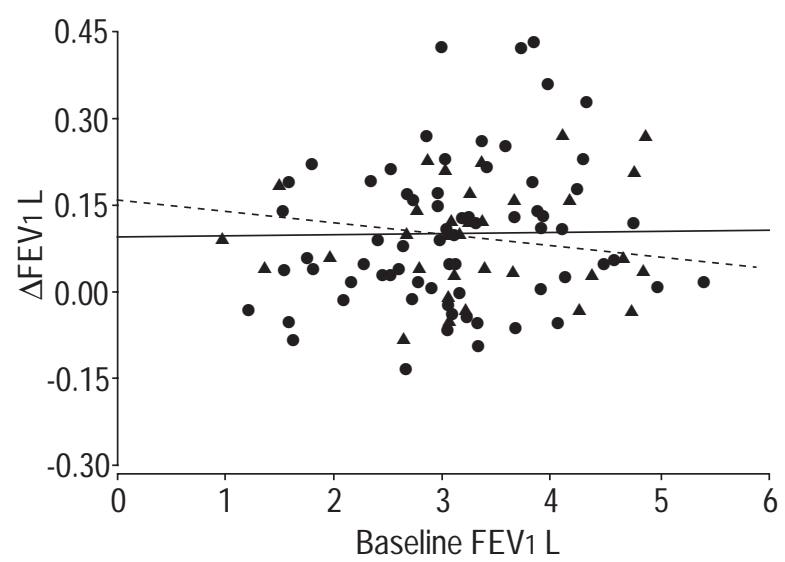

Fig. 2. - Correlation between change in $(\Delta)$ forced expiratory volume in one second (FEV1) following bronchodilator challenge and measured baseline FEV1 in nonsmoking adult first-degree relatives of chronic obstructive pulmonary disease probands $(\mathbf{0} ;-$ : regression line; Spearman $=0.09, \mathrm{p}=0.46)$ and current/exsmoking controls $(\boldsymbol{\Delta} ;-\cdots$ regression line $=0.03, \mathrm{p}=0.88$ ). develop COPD [24]. $\alpha_{1}$-Antitrypsin deficiency is a welldocumented genetic risk factor for COPD, but it accounts for only a small proportion of cases [25]. In order to identify genetic risk factors for COPD other than $\alpha_{1}$ antitrypsin deficiency, a group of 44 probands with severe early-onset COPD and 203 of their first-degree relatives was assembled [6]. Efforts were concentrated on subjects without severe $\alpha_{1}$-antitrypsin deficiency developing severe COPD at an early age, since the likelihood of finding a significant genetic contribution to their disease may be greater, analogous to other complex illnesses [26]. In currently smoking or exsmoking adult first-degree relatives of early-onset COPD probands, increased bronchodilator responsiveness was found compared with currently smoking or exsmoking adult controls. In contrast. there was no significant difference in bronchodilator responsiveness between nonsmoking first-degree relatives of probands with severe early-onset COPD and nonsmoking controls.

The results of the population-based retrospective cohort study of VoLLMER et al. [14] did show a positive correlation between bronchodilator response and the subsequent yearly decline in FEV1, which remained unchanged after restricting the analysis to subjects with abnormal FEV1 at baseline. Five longitudinal case-series studies that prospectively examined the relationship of bronchodilator responsiveness to the rate of decline in FEV1 among patients with chronic airflow obstruction have yielded conflicting results, finding either positive [15-17] or negative correlations $[27,28]$. Possible explanations for the disagreement among these studies include confounding by baseline FEV1, treatment effects and analytical differences [29]. Since direct assessment of airway responsiveness to methacholine or histamine was impractical for probands and relatives with severe airflow obstruction, bronchodilator response was measured as a potential intermediate (disease-related) phenotype of COPD.

In the Lung Health Study (LHS), a large prospective cohort study of smokers with mild-to-moderate airflow limitation, TASHKIN et al. [30] observed $\triangle \mathrm{FEV} 1$ ranging 
from $75 \pm 85 \mathrm{~mL}$ in females without airway hyperresponsiveness to $132 \pm 151 \mathrm{~mL}$ in males with airway hyperresponsiveness. In the currentt study, the authors observed a $\triangle F E V 1$ of $120 \pm 130 \mathrm{~mL}$ among 111 currently smoking and exsmoking first-degree relatives of early-onset COPD probands that were not selected on the basis of their lung function. In a large health survey of children and adults conducted in Alberta (Canada), DALES et al. [31] observed a $\triangle F E V 1$ of $68 \pm 129 \mathrm{~mL}$ among 2,609 participants. In the present study a $\triangle F E V 1$ of $80 \pm 120 \mathrm{~mL}$ was observed among the 83 adult controls, which is consistent with the survey findings of DALES et al. [31]. The observed $\triangle \mathrm{FEV} 1$ in the present smoking controls $(60 \pm 110 \mathrm{~mL})$ was lower than the $\triangle \mathrm{FEV} 1$ among the LHS participants, probably reflecting differences in the selection processes of the study samples. However, the possibility of having unintentionally selected former and current smokers with decreased bronchodilator responsiveness into the control group of the present study cannot be completely excluded.

The increased bronchodilator responsiveness in current smokers or exsmokers who were first-degree relatives of early-onset COPD probands may be related to their lower level of lung function. However, the inclusion of measured baseline FEV1 in the multivariate models did not appreciably change the observed difference in bronchodilator responsiveness between the groups, particularly after excluding asthmatic subjects from the control group. Thus, heightened bronchomotor tone and/or undefined inflammatory processes may be partially responsible for the greater response to bronchodilator administration among former and current smokers who are first-degree relatives of earlyonset COPD probands [29].

The increased bronchodilator responsiveness in currently smoking or exsmoking first-degree relatives of probands with severe early-onset COPD may be caused by genetic or shared environmental factors. Even though smoking-related exposures were adjusted for, it is possible that other unmeasured factors (e.g. childhood home passive smoke exposure) may explain the increased bronchodilator responsiveness in currently smoking or exsmoking first-degree relatives of COPD probands; however, no strong evidence was found that they are critical determinants of COPD in the present pedigrees [6].

In previous work, increased total serum IgE levels were found in first-degree relatives of PI Z subjects with COPD [18]. Elevated total serum IgE levels in first-degree relatives of early-onset COPD probands were not found compared with control subjects, even after excluding asthmatic subjects from the control group. Thus, the present findings suggest that families of probands with severe early-onset COPD are not highly atopic.

In summary, increased bronchodilator responsiveness was found among current smokers or exsmokers who are first-degree relatives of probands with severe early-onset chronic obstructive pulmonary disease. Relative risks for forced expiratory volume in one second $<60 \%$ pred, forced expiratory volume in one second $<80 \%$ pred, and chronic bronchitis of approximately three for currently smoking or exsmoking first-degree relatives of probands with severe early-onset chronic obstructive pulmonary disease have previously been reported [6]. All of these findings suggest that first-degree relatives of subjects with severe, earlyonset chronic obstructive pulmonary disease show increased susceptibility to the effects of cigarette smoking.

\section{References}

1. Feinleib M, Rosenberg HM, Collins JG, Delozier JE, Pokras R, Chevarley FM. Trends in COPD morbidity and mortality in the United States. Am Rev Respir Dis 1989; 140: S9-S18.

2. Kochanek KD, Hudson BL. Advance report of final mortality statistics, 1992. Mon Vital Stat Rep 1995; 43: 173.

3. Silverman EK, Speizer FE. Risk factors for the development of chronic obstructive pulmonary disease. Med Clin North Am 1996; 80: 501-522.

4. US Department of Health and Human Services. The health consequences of smoking: chronic obstructive lung disease. A report of the Surgeon General. US Department of Health and Human Services, Office on Smoking and Health, Bethesda, MD. 1984. (DHHS Publication No. (PHS)84-50205).

5. Burrows B, Knudson RJ, Cline MG, Lebowitz MD. Quantitative relationships between cigarette smoking and ventilatory function. Am Rev Respir Dis 1977; 115: 195205.

6. Silverman EK, Chapman HA, Drazen JM, et al. Genetic epidemiology of severe, early-onset chronic obstructive pulmonary disease. Risk to relatives for airflow obstruction and chronic bronchitis. Am J Respir Crit Care Med 1998; 157: 1770-1778.

7. Lewitter FI, Tager IB, McGue M, Tishler PV, Speizer FE. Genetic and environmental determinants of levels of pulmonary function. Am J Epidemiol 1984; 120: 518529.

8. Redline S, Tishler PV, Rosner B, et al. Genotypic and phenotypic similarities in pulmonary function among family members of monozygotic and dizygotic twins. Am J Epidemiol 1989; 129: 827-836.

9. Hankins D, Drage C, Zamel N, Kronenberg R. Pulmonary function in identical twins raised apart. Am Rev Respir Dis 1982; 125: 119-121.

10. Webster PM, Lorimer EG, Man SFP, Woolf CR, Zamel N. Pulmonary function in identical twins: comparison of nonsmokers and smokers. Am Rev Respir Dis 1979; 119: 223228.

11. Larson RK, Barman ML, Kueppers F, Fuedenberg HH. Genetic and environmental determinants of chronic obstructive pulmonary disease. Ann Intern Med 1970; 72: 627-632.

12. Kueppers F, Miller RD, Gordon H, Hepper NG, Offord K. Familial prevalence of chronic obstructive pulmonary disease in a matched pair study. Am J Med 1977; 63: 336342.

13. Cohen BH, Ball Jr WC, Brashears S, et al. Risk factors in chronic obstructive pulmonary disease (COPD). Am J Epidemiol 1977; 105: 223-232.

14. Vollmer WM, Johnson LR, Buist AS. Relationship of response to a bronchodilator and decline in forced expiratory volume in one second in population studies. Am Rev Respir Dis 1985; 132: 1186-1193.

15. Kanner RE. The relationship between airways responsiveness and chronic airflow limitation. Chest 1984; 86 : $54-57$.

16. Campbell AH, Barter CE, $\mathrm{O}^{\prime}$ Connell JM, Huggins R. Factors affecting the decline of ventilatory function in chronic bronchitis. Thorax 1985; 40: 741-748.

17. Taylor RG, Joyce H, Gross E, Holland F, Pride NB. Bronchial reactivity to inhaled histamine and annual rate of decline in FEV1 in male smokers and exsmokers. Tho$\operatorname{rax} 1985$; 40: 9-16. 
18. Silverman EK, Province MA, Rao DC, Pierce JA, Campbell EJ. A family study of the variability of pulmonary function in alpha-1-antitrypsin deficiency. Quantitative phenotypes. Am Rev Respir Dis 1990; 142: 10151021.

19. Dockery DW, Ware JH, Ferris Jr BG, et al. Distribution of forced expiratory volume in one second and forced vital capacity in healthy, white, adult never-smokers in six US cities. Am Rev Respir Dis 1985; 131: 511-520.

20. Tager IB, Rosner B, Tishler PV, Speizer FE, Kass EH. Household aggregation of pulmonary function and chronic bronchitis. Am Rev Respir Dis 1976; 114: 485-492.

21. Ferris BG. Epidemiology standardization project. Am Rev Respir Dis 1978; 118 (Suppl.): 1-120.

22. Gardner RM, Hankinson JL, Clausen JL, Crapo RO, Johnson Jr. RL, Epler GR. Standardization of spirometry: 1987 update. Official statement of the American Thoracic Society. Am Rev Respir Dis 1987; 136: 1285-1298.

23. Crapo RO, Morris AH, Gardner RM. Reference spirometric values using techniques and equipment that meet ATS recommendations. Am Rev Respir Dis 1981; 123: 659-664.

24. Kuperman AS, Riker JB. The variable effect of smoking on pulmonary function. Chest 1973; 63: 655-660.

25. Lieberman J, Winter B, Sastre A. Alpha-l-antitrypsin
Pi-Types in 965 COPD patients. Chest 1986; 89: 370 373.

26. Hall JM, Lee MK, Newman B, et al. Linkage of earlyonset familial breast cancer to chromosome 17q21. Science 1990; 250: 1684-1689.

27. Postma DS, de Vries K, Koeter GH, Sluiter HJ. Independent influence of reversibility of airflow obstruction and nonspecific hyperreactivity on the long term course of lung function in chronic airflow obstruction. Am Rev Respir Dis 1986; 134: 276-280.

28. Anthonisen NR, Wright EC, and the IPPB Trial Group. Bronchodilator response in chronic obstructive pulmonary disease. Am Rev Respir Dis 1986; 133: 814-819.

29. O'Connor GT, Sparrow D, Weiss ST. The role of allergy and nonspecific airway hyperresponsiveness in the pathogenesis of chronic obstructive pulmonary disease. $\mathrm{Am}$ Rev Respir Dis 1989; 140: 225-252.

30. Tashkin DP, Altose MA, Bleecker ER, et al. The Lung Health Study: airway responsiveness to inhaled methacholine in smokers with mild to moderate airflow limitation. Am Rev Respir Dis 1992; 145: 301-310.

31. Dales R, Spitzer WO, Tousignant P, Schechter M, Suissa $\mathrm{S}$. Clinical interpretation of airway response to a bronchodilator. Epidemiologic considerations. Am Rev Respir Dis 1988; 138: 317-320. 